\title{
Proteins of Human Urine. III. Identification and Two-Dimensional Electrophoretic Map Positions of Some Major Urinary Proteins
}

\author{
Jesse J. Edwards, ${ }^{1}$ Sandra L. Tollaksen, and Norman G. Anderson
}

\begin{abstract}
We mapped the proteins of human urine by high-resolution two-dimensional electrophoresis, utilizing the ISO-DALT system. Wide-range $\mathrm{pH}$ gradients and narrow-range acid gradients were both used in the first-dimension separations. The patterns revealed proteins ranging in relative molecular mass from 10000 to 90000 . Proteins identified in the map included transferrin, albumin, hemopexin, $\alpha_{2}$-HS glycoprotein, $\alpha_{1}$-antitrypsin, Gc globulin, $\alpha_{1}$-acid glycoprotein, Zn $\alpha_{2}$-glycoprotein, retinol binding protein, $\beta_{2}$-microglobulin, the immunoglobulin light chains, and MAUP (most acid urinary protein). The use and utility of internal-charge and molecular-mass standards are described. We used electrophoretic transfer of proteins to nitrocellulose sheets and subsequent detection by immunological methods to identify some proteins.
\end{abstract}

\section{Additional Keyphrases: ISO-DALT system - multiple myeloma - identification by transfer to nitrocellulose sheet, followed by use of monospecific antisera - standards for internal charge $(p /)$ and molecular mass}

The protein composition of human urine and the relative quantities of different proteins are generally considered to be clinically significant. In many instances, the composition of urine may reflect changes in the biochemical and physiological status of an individual. Recently, human urinary proteins were classified into eight groups (1) and assessment of members of each group was postulated to have possible diagnostic value. For this reason, it is necessary to investigate, as sensitively as possible, both the qualitative and quantitative changes that occur in the proteins of urine under different clinical conditions. Recent findings (2-4) support earlier observations that both quantitative and qualitative alterations in urinary proteins are associated with trauma or disease.

Normal human urine is a complex mixture of proteins and many components of low molecular mass. Protein is present in low concentrations, approximately $100 \mathrm{mg} / \mathrm{L}$, the normal excretion rate being about $20-100 \mathrm{mg}$ per 24 hours (5). The concentration of proteins in urine is therefore about $0.14 \%$ that of blood plasma (6). These facts are central to several fundamental problems that have plagued studies of urinary protein.

The first problem is concerned with the need to concentrate the proteins. Generally, about a 1000-fold concentration is desired, with concomitant removal of salts and other lowmolecular-mass material, so that the protein moiety can be analyzed. Various concentration methods have been used in the past, including precipitation (7), pervaporation, dialysis, and ultrafiltration (8). Adsorption techniques have also been used (9).

A second problem involves the physical recovery and quantitation of proteins that exist in an almost continuous range of relative molecular masses, from values in the millions

Molecular Anatomy Program, Division of Biological and Medical Research, Argonne National Laboratory, Argonne, IL 60439.

${ }^{1}$ Present address: Department of Pathology, University of North Carolina Medical School, Chapel Hill, NC 27514. for the Tamm-Horsfall proteins, through those found in plasma down to very small proteins such as peptide hormones and, presumably, catabolic fragments.

Thirdly, there is the problem of resolving the hundreds of protein species, which are present in various amounts. New technology in protein separation methods has to be applied that will allow the different proteins to be detected and will permit simultaneous analysis of multiple samples.

Finally to be solved are the problems of protein identification and the determination of the tissue, cell type, and subcellular components from which the proteins originate.

We have begun to approach these problems systematically in an effort to produce new methodology and to utilize existing techniques for reproducibly evaluating urinary proteins. Concentration methods have been developed $(10,11)$ that yield sufficiently pure preparations to allow physical recovery to be determined gravimetrically and that give samples that yield almost identical results. The recovered urinary proteins are resolved by two-dimensional electrophoresis. After denaturation to monomeric subunits, the proteins are separated on the semi-automated ISO-DALT electrophoretic system, which permits multiple sample resolution of complex mixtures of proteins (12-14). The individual proteins thus resolved are identified by position, by co-electrophoresis with purified proteins, and by immunological reactivity with monospecific antisera. Identification by map position requires the use of internal position markers, which have previously been developed $(15,16)$.

The utility of two-dimensional electrophoretic methods for identifying alterations in urinary proteins that are related to specific pathological conditions has been demonstrated in two recent publications $(17,20)$. The quantitative and qualitative changes shown could not have been demonstrated by any other present-day analytical methods.

The purpose of this paper is to describe the most recent procedures that we have developed for mapping and identifying normal urinary proteins. Modifications of our earlier methods of concentration, desalting, and recovery of urinary protein are given, and the methods and the materials presented in the following section are those we now currently use. We also describe the determination of coordinate map positions for many proteins, and the identification of a number of proteins. A set of examples from the urine of multiple myeloma patients is included to demonstrate the potential of the procedure for distinguishing pathological conditions.

\section{Materials and Methods}

\section{Materials}

Bio-Gel P-6, polyacrylamide gel beads for high-resolution gel filtration, was purchased from Bio-Rad Laboratories, Richmond, CA 94802. An ultraviolet absorption monitor, Model UA-5, was purchased from ISCO, Inc., Lincoln, NE 68505. Ampholytes for isoelectric separations were from LKB, Bromma, Sweden, and from Serva Fine Biochemicals, Inc., Garden City Park, NY 11040. Antibodies to human proteins were purchased from DAKO (via Accurate Chemical and Scientific Corp., Westbury, NY 11590). Nitrocellulose paper, type 


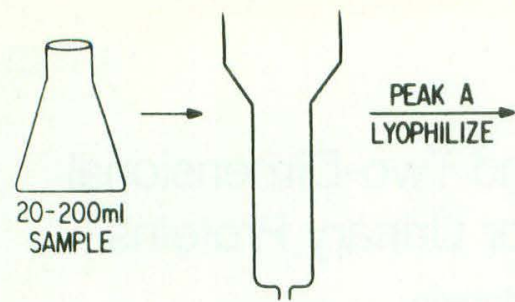

P-6 BNO-GEL

$1.7 \mathrm{~L}$ COLUMN
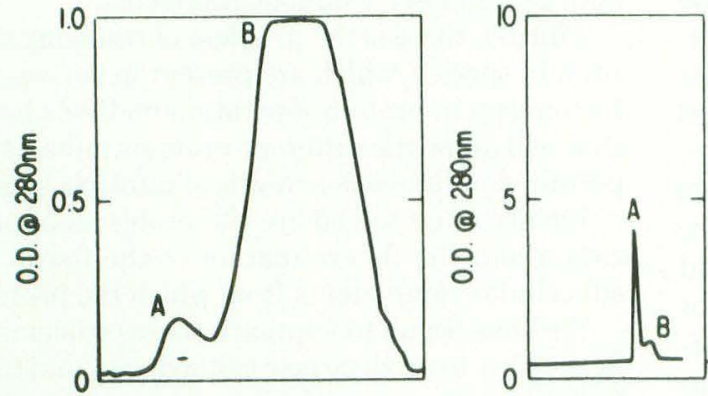

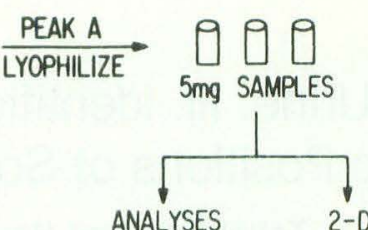

Enzyme, protein

etc.)

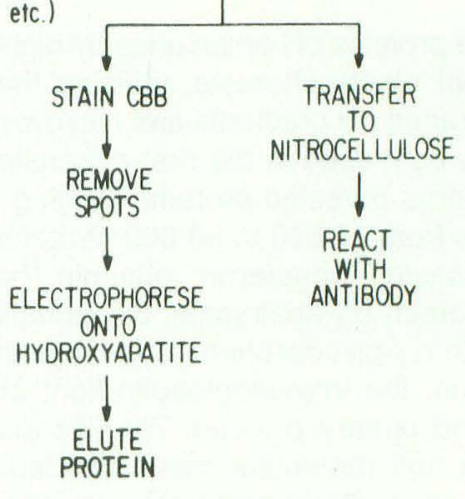

Fig. 1. Diagrammatic representation of the steps performed in the concentration and desalting of human urine samples

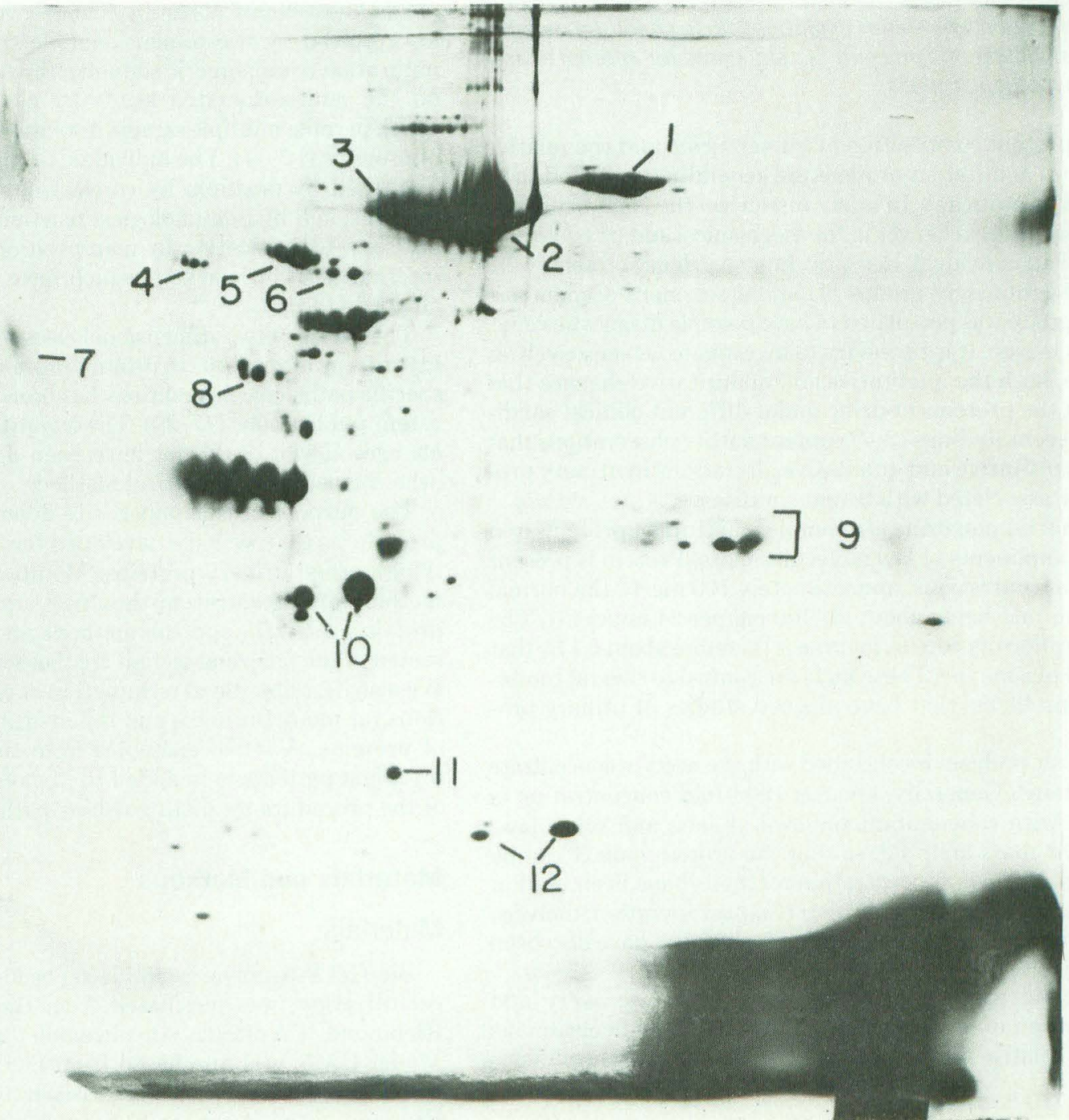

Fig. 2. Two-dimensional electrophoretic pattern of urinary proteins of a normal male

The gel is oriented with the acidic side to the left. Identified proteins are: 1 , transferrin; 2 , albumin; 3 , hemopexin; $4, \alpha_{2}$-HS glycoprotein; $5, \alpha_{1}$-antitrypsin; $6, g$, Gc globulin; 7, $\alpha_{1}$-acid glycoprotein (orosomucoid); $8, \mathrm{Zn} \alpha_{2}$-glycoprotein; 9, IgG light chains; 10, retinol binding protein; 11, prealbumin; 12, $\beta_{2}$-microglobulin 


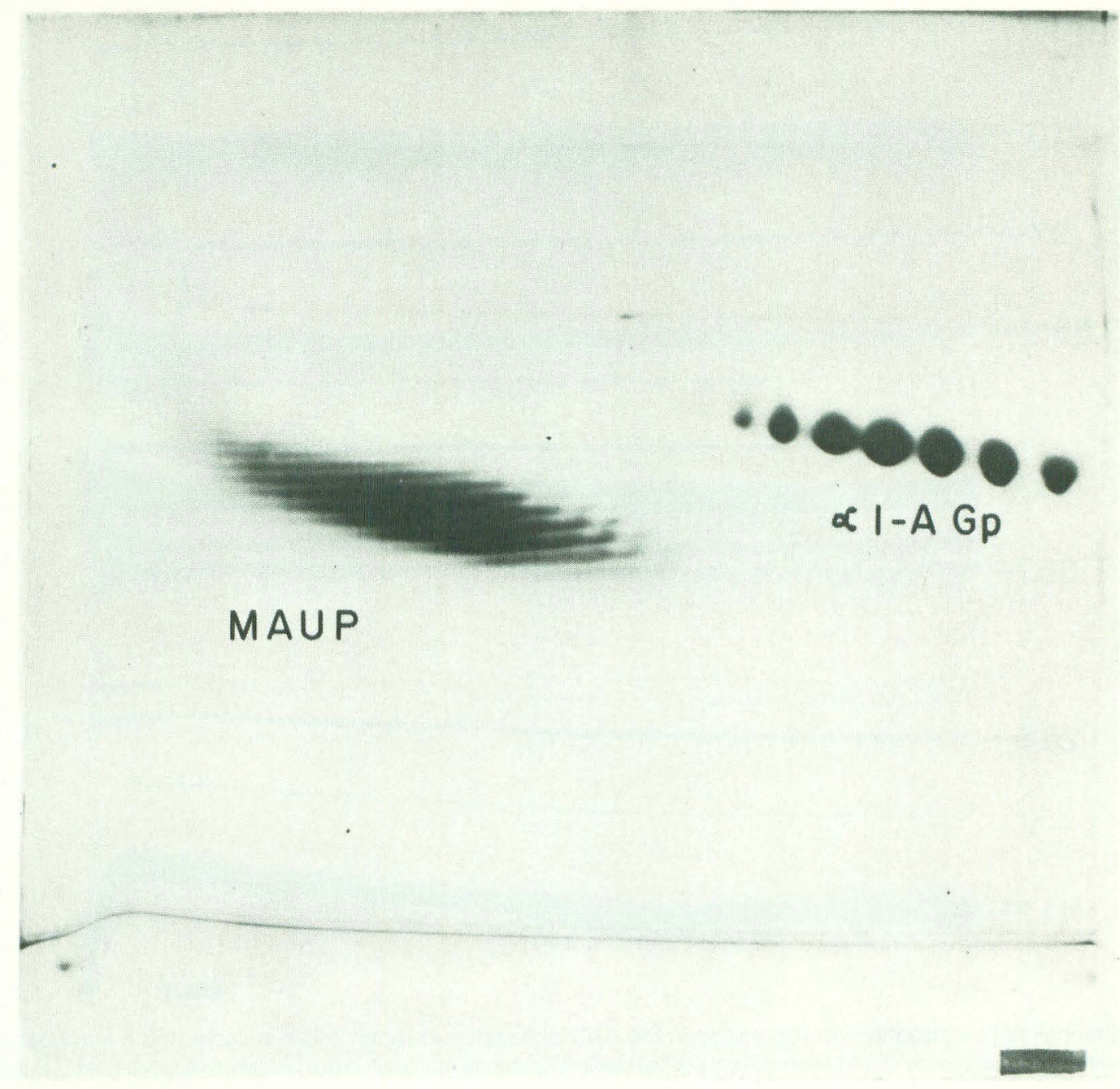

Fig. 3. Two-dimensional electrophoretic pattern of acid proteins of human urine

Gel is oriented as in Figure 2. Identified proteins are MAUP (most acid urinary protein) and $\alpha_{1}$-acid glycoprotein

BA85, was from Schleicher and Schuell, Keene, NH 03431. Conical-bottom 250-mL polypropylene disposable centrifuge tubes were from Corning Glass Works, Chicago, IL 60631. An assortment of purified proteins was obtained from Behringwerke, Marburg, F.R.G.

\section{Methods}

Centrifugation and desalting of urinary proteins. Urine samples (generally 20-200 mL) were collected in the $250-\mathrm{mL}$ centrifuge tubes. Sodium azide was added to give a final concentration of $2 \mathrm{mg} / \mathrm{L}$ to prevent bacterial growth. Cells and other nonsoluble material were cleared from the sample by centrifugation at low speed $(2000 \times \mathrm{g}, 15 \mathrm{~min})$. Pelleted material was quickly frozen by immersing the conical bottom of the tube into a solid- $\mathrm{CO}_{2}$ /ethanol bath at $-78^{\circ} \mathrm{C}$.

The liquid portion of the sample was then applied to a $6 \times$ $40 \mathrm{~cm}$ column of Bio-Gel P-6 that previously had been equilibrated with glass-distilled water. When distilled water was applied to the column, high-molecular-mass material (above approximately 6000 daltons) emerged ahead of salts and other low-molecular-mass material. The effluent was monitored for protein by following the ultraviolet absorbance at $280 \mathrm{~nm}$ with an ISCO Model UA-5 absorbance monitor equipped with a $0.5-\mathrm{cm}$ pathlength flow cell. Effluent corresponding to the protein peak, which emerged with the void volume, was collected and lyophilized.

This lyophilized nonhygroscopic powder was resuspended in $5 \mathrm{~mL}$ of distilled water and applied to a second, smaller $(2.5$ $\times 25 \mathrm{~cm}$ ) column of Bio-Gel P-6, also equilibrated with water. Just before the sample, $5 \mathrm{~mL}$ of $1 \mathrm{~mol} / \mathrm{L} \mathrm{NaCl}$ was applied to the column. As the protein sample passes through this zone of high salt concentration it is freed of adsorbed materials. The effluent from this column was monitored as before, except that we used a $0.2-\mathrm{cm}$ pathlength flow cell. The protein peak eluting with the void volume was collected and lyophilized in a tared flask.

The weight of the protein powder was determined and the sample was solubilized in distilled water to give a final concentration of $25 \mathrm{~g} / \mathrm{L}$. Aliquots of $200 \mu \mathrm{L}$ containing $5 \mathrm{mg}$ of protein were frozen and lyophilized in microcentrifuge tubes and the residue was stored at $-80{ }^{\circ} \mathrm{C}$ until analysis. For electrophoresis, samples were solubilized to give a final concentration of $100 \mathrm{~g} / \mathrm{L}$ in a buffer containing, per liter, $9 \mathrm{~mol}$ of urea, $20 \mathrm{~g}$ of dithioerythritol, and $40 \mathrm{~mL}$ of LKB Ampholine, $\mathrm{pH} 3.5-10$. Generally, we used 750 to $1000 \mu \mathrm{g}$ of protein for each electrophoretic sample.

Handling of purified proteins. The purified proteins we used were each solubilized to give a final concentration of 5 $\mathrm{g} / \mathrm{L}$ in the buffer described above. For electrophoretic analysis, or for co-electrophoresis with urine samples, $2 \mu \mathrm{L}(10 \mu \mathrm{g})$ of such a solution was applied to each gel.

Two-dimensional electrophoresis. Both urinary proteins and purified proteins were separated electrophoretically with use of the ISO-DALT system $(12,13)$ to resolve acidic and neutral proteins. Very acid proteins were resolved in the first dimension on a modified $\mathrm{pH}$ gradient. 


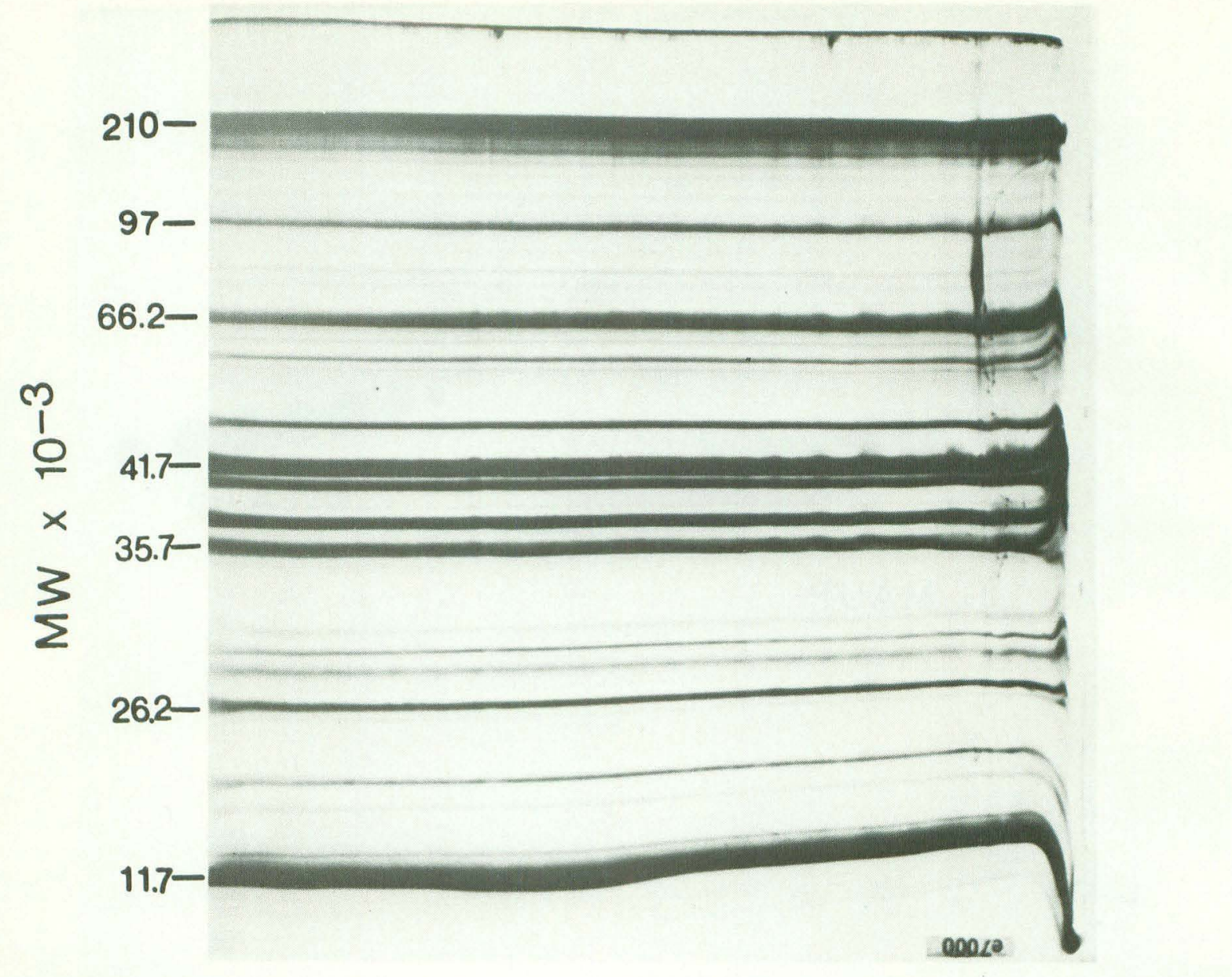

Fig. 4. One-dimensional electrophoretic separation in the DALT dimension of rabbit psoas muscle whole homogenate Molecular mass values were obtained by co-electrophoresis of purified rabbit muscle proteins, human serum albumin, and equine heart cytochrome $c$

Focusing in the first-dimension ISO gels was done in $40 \mathrm{~g} / \mathrm{L}$ polyacrylamide containing, per liter, $2.4 \mathrm{~g}$ of $N, N$-methylenebisacrylamide as cross-linker, $9 \mathrm{~mol}$ of urea, $50 \mathrm{~mL}$ of ampholytes (80\% Servalyt 3-10 and 20\% LBK Ampholyte 5-7) and $20 \mathrm{~mL}$ of Nonidet P40 detergent (Particle Data Labs, Elmhurst, IL 60126) for $10000 \mathrm{~V} \cdot \mathrm{h}$. Highly acidic proteins were electrophoresed for $4000 \mathrm{~V} \cdot \mathrm{h}$ on gels of similar composition, except that the $\mathrm{pH}$ gradient was expanded in the acid range by using $85 \mathrm{~mL}$ of Servalyt (76\% 2.5-4 and 24\% 3-10) per liter.

Molecular mass separations in the second dimension were in slab gels consisting of a linear polyacrylamide gradient $(80-200 \mathrm{~g} / \mathrm{L}$, and containing $8 \mathrm{~g}$ of cross-linker per liter). The electrophoretic buffer was the Tris-glycine-sodium dodecyl sulfate solution previously described (13).

Isoelectric and molecular mass standards. As internal charge standards for the first-dimension isoelectric focusing step, we used carbamylated creatine kinase (EC 2.7.3.2) from rabbit muscle (Sigma Chemical Co., St. Louis, MO 63178) as previously described (16).

Molecular mass standards were prepared as follows. A homogenate of fresh rabbit psoas muscle was prepared by mincing the tissue in 10 volumes of pyrophosphate relaxing buffer (18). After 30 min the tissue was transferred to 10 volumes of low salt buffer (18), homogenized for $60 \mathrm{~s}$ in a Waring Blendor, and then filtered through four layers of cheese cloth to remove connective tissue. The filtrate was diluted with four volumes of melted agarose solution containing, per liter, $10 \mathrm{~g}$ of agarose, $19.75 \mathrm{~g}$ of Tris $\mathrm{HCl}, 10 \mathrm{~g}$ of sodium dodecyl sulfate, and $5 \mathrm{~g}$ of dithioerythritol. Human serum albumin and equine heart cytochrome $c$ were added to give a final concentration of $1.0 \mathrm{~g} / \mathrm{L}$. The solution was stored in 5 -mL aliquots at $-80^{\circ} \mathrm{C}$.

When used in the second-dimension DALT separation, an aliquot of the muscle preparation was melted and drawn into a 0.2 -mL glass pipette, allowed to solidify, then expressed as a slender rod. For inclusion on each DALT gel, a small portion $(\sim 1.5 \mathrm{~cm})$ of this muscle standard was placed at the acid end of the first-dimension ISO gel, and held in place with the ISO gel by melted agarose (15). Molecular-mass values were determined by co-electrophoresis with purified proteins, including those isolated from rabbit muscle.

Spot identification. Protein subunits in the urine map were identified by co-electrophoresis with purified proteins, or by immunological procedures, or by both methods.

Protein subunits were identified immunologically after electrophoretic transfer of the pattern from the second-dimension DALT gel to type BA85 nitrocellulose paper, essentially as described by Towbin et al. (19). The transferred protein patterns were treated with monospecific antiserum, and the precipitated antigen-antibody complex was reacted with horseradish-peroxidase-conjugated IgG vs the first antibody. The complex was then made visible by treatment with 3',3-diaminobenzidine tetrahydrochloride. A detailed description of the transfer and detection process used here will be published elsewhere (28).

\section{Results}

Figure 1 diagrams the procedure we follow to concentrate and desalt human urinary proteins. As described, the resulting protein material is stored as small aliquots of dried powder, which are subsequently used for two-dimensional electro- 


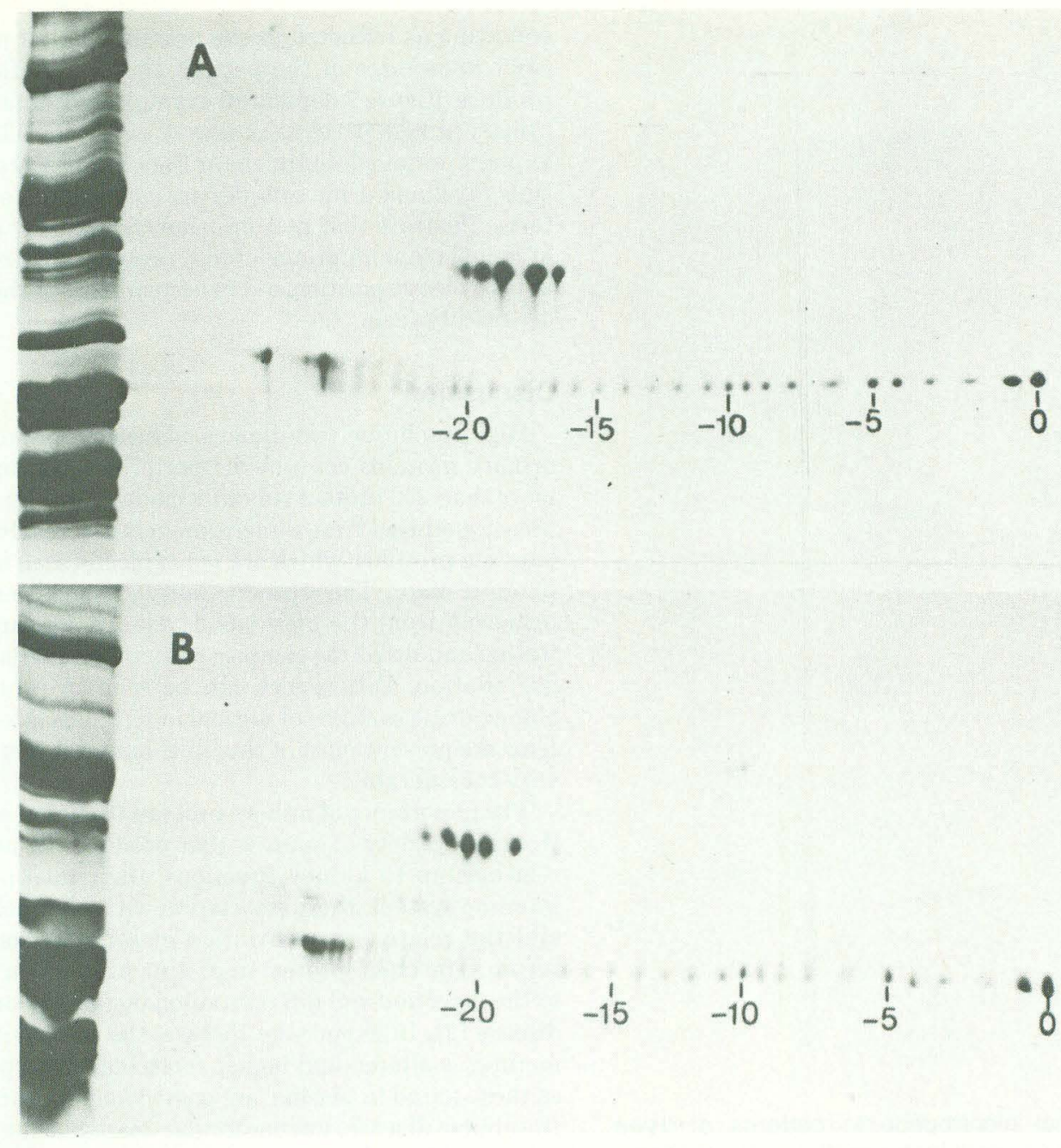

Fig. 5. Two-dimensional electrophoretic pattern of two purified proteins commonly found in human urine Patterns include both charge and molecular mass standards. The relationships of $(A)$ Gc globulin and $(B) \alpha_{1}$-antitrypsin to each other and to the standards are shown

phoresis. The diagram also shows other steps that can follow two-dimensional electrophoretic mapping. Purified protein can be obtained from the gel and then used for antiserum production, amino acid analysis, or determination of chemical composition. The gel may be used to transfer specific proteins to paper for study of immunological reactions.

An electrophoretic pattern obtained for urinary proteins from a normal man is shown in Figure 2. Most of the proteins are typically present in maps from different individuals, although quantitative differences are considerable. (The blur at the bottom is due to stained ampholytes.) This map is very similar to that recently published by Frearson et al. (20), except that our maps generally lack significant amounts of Tamm-Horsfall antigen. This difference is probably due to the removal of this material during our initial centrifugation step, which is omitted by others, or it is lost during the initial desalting procedure possibly by adsorption onto P-6 BioGel.

The molecular-mass range of proteins separated by our methods is between 10000 and 90000 daltons, with many of the forms showing charge heterogeneity indicative of a glycoprotein nature. The urinary protein map resembles that of human plasma (21); of the proteins identified in Figure 2, most are known components of blood plasma, including transferrin, albumin, hemopexin, Gc globulin, $\alpha_{1}$-antitrypsin, $\alpha_{1}$-antichymotrypsin, $\alpha_{1}$-acid glycoprotein, the immunoglobulin light chains, and prealbumin.
Some proteins were not well resolved on wide-pH-range focusing gels. For this reason narrow-range, very acid ampholytes were used to resolve these proteins (Figure 3 ). The larger and more basic proteins, on the right, are resolved into seven horizontally separated spots, which slope upward and to the left. This slope is thought to reflect the post-translational addition of carbohydrate residues, which not only increases the molecular mass but also provides sites for the addition of more sialic acid (neuraminic acid) residues. When urine and serum from the same individual were electrophoresed in various ratios, the urine spots were superimposed over the previously identified (22) serum $\alpha_{1}$-acid glycoprotein. This superimposition suggests that they are the same protein.

The complex of spots identified as MAUP (the $m$ ost $a \mathrm{cid}$ $u$ rinary protein, 22) in Figure 3 resolves into many bands, each composed of individual spots. Little is known of the nature of this protein complex, especially concerning the properties that give it such a unique two-dimensional banding pattern The origin of MAUP is also unknown, but different patterns are seen in samples from different individuals (22).

Figure 4 shows a one-dimensional separation of rabbit psoas muscle performed as described in Methods. This preparation is used as an aid in estimating the molecular mass of proteins separated by two-dimensional electrophoresis. The muscle preparation was applied to a DALT gel and electrophoresed only in the second dimension of the ISO-DALT procedure. The number of lines provided by this preparation provides a mo- 
A

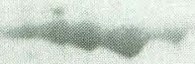

B

$+4$

C

Fig. 6. Two-dimensional electrophoretic patterns of three proteins after transfer to nitrocellulose, reaction with antiserum, and staining as described in Methods

$(A)$ transferrin, $(B)$ Gc globulin, and $(C) \beta_{2}$-microglobulin

lecular mass correlation for spots in almost any position on the map. This type of standard greatly aids in (e.g.) locating the position of a protein for which the molecular mass is known (15).

Figure 5 shows two-dimensional electrophoretic patterns, with both charge and molecular weight standards, of two purified proteins that are commonly found in human urine. Co-electrophoresis of these proteins with human urinary proteins provided one method for the identification of urinary proteins in the two-dimensional maps. The internal standards run with the purified proteins provide map coordinates for the location of proteins in complex mixtures. For example, it is known that the vitamin D-binding protein, Gc globulin, has a relative molecular mass of 59000 , and it can be seen in Figure $5 \mathrm{~A}$ that it focuses at -17 to -21 creatine kinase charge units. Other proteins in map patterns can be tentatively identified in this manner.

The patterns of protein shown in Figure 6 were photographed from nitrocellulose transfers of two-dimensional maps of human urinary proteins. The transfers were reacted with antiserum to the specific protein, then stained. The unambiguous identification of proteins, protein subunits, and degradation components in urine by this method of course depends upon the specificity of the antisera used in the first-stage antigen-antibody complex (28).

One of the most important uses of two-dimensional protein mapping of human urinary proteins is for the early detection of disease states. A prerequisite for recognizing a pathological condition as reflected in the protein content of the urine is prior knowledge of the pattern that a specific disease will produce. Figure 7 depicts an example of dramatic changes in urinary protein patterns as a result of disease. The lambda and kappa immunoglobulin chain Bence Jones proteins of multiple myeloma urine samples are easily detected. These patterns illustrate that no confusion should exist as to the type of monoclonal immunoglobulin present, because differences in both charge position and molecular mass of the two proteins are readily seen.

\section{Discussion}

High-resolution two-dimensional electrophoresis of human urinary proteins can now be performed reproducibly, with more than 200 protein subunits made visible by staining. The use of modified first-dimension gels can resolve very acidic banding proteins, which are not typically seen in the electrophoretic maps. The reproducibility of the patterns is derived primarily from the methods developed for rapidly concentrating and desalting samples with minimal loss of protein or degradation. Differences can be seen in protein patterns among urine samples of normal individuals. Most of the proteins are present most of the time, but their relative amounts vary considerably.

The importance of urinary proteins to clinical analysis arises from the variety of sources that produce the proteins, their relationship to kidney functions, their relationship to the immune system, their association with metabolic disorders, and the relative concentration of some as compared with serum. The chief interest in plasma proteins in urine relates to the detection and differentiation of glomerular and tubular disease (2). In glomerular disease, the selectivity of the glomerulus is altered and higher-molecular-mass proteins, such as those found in plasma, are passed and appear in the urine. In tubular disease, low-molecular-mass plasma proteins are not properly reabsorbed and appear in the urine. These general characteristics of the two disorders have been known for a long time. Many plasma proteins have been identified in the urine and their presence in large amounts may be of diagnostic importance.

Orosomucoid, or $\alpha_{1}$-acid glycoprotein as it exists in the urine, originates in part from a fragment of an externally located integral membrane protein of leukocytes, which is apparently released in vivo (23). Increases in its concentration in serum and (presumably) urine suggest disorders involving leukocyte proliferation. In urine this protein appears in multiple forms, depending upon the degree of sialylation.

$\beta_{2}$-Microglobulin is normally a component of cell membranes, is associated with histocompatibility antigens, and has a partial sequence homology with the heavy chain of IgG. The increase in excretion of proteins of low molecular mass in disease involving the proximal tubule was first shown by Friberg (24) in workers with cadmium poisoning. Among these proteins, $\beta_{2}$-microglobulin is accepted as an indicator of tubular damage due to heavy metal poisoning.

Retinol-binding protein, which functions in the transport of vitamin A, increases in the urine after renal transplantation or cadmium poisoning (25).

The vitamin-D-binding protein, Gc globulin, has been demonstrated to increase in the nephrotic syndrome (26) and is probably an indicator of glomerular damage.

Immunoglobulin derivatives have long been considered diagnostic in diseases such as multiple myeloma in which there is a production of excess monoclonal light chains, which appear in the urine. Both the amount and nature of the monoclonal components have prognostic value. The higher association constants of lambda chains as compared with kappa chains may be clinically important in view of the associated 

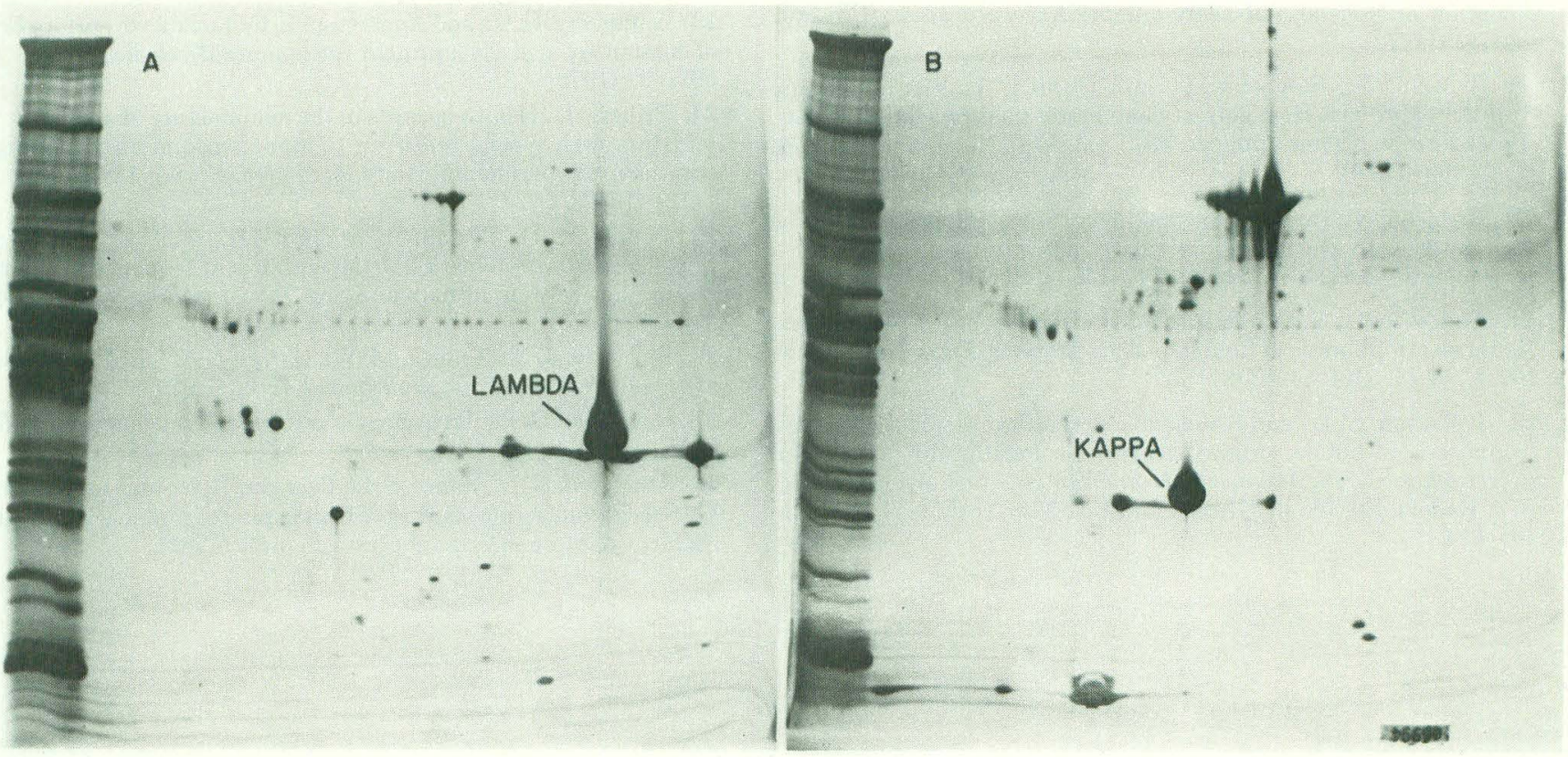

Fig. 7. Two-dimensional electrophoretic patterns of human urine from two multiple myeloma patients

An immunoglobulin chain of lambda-type Bence Jones protein is shown in $(A)$; a kappa-type monoclonal Bence Jones protein is shown in (B)

increase in renal impairment and poorer prognosis for those multiple myeloma patients with lambda type Bence Jones proteinuria (27).

It is essential to identify as many urinary proteins as possible to aid in the assessment of the usefulness of each as indicators of disease or trauma; as the number of spots identified increases, two-dimensional maps increase proportionally in usefulness. A continued systematic approach to spot identification is therefore necessary. This includes the identification not only of proteins of plasma origin but also of proteins from the seven other possible sources of urinary proteins we described earlier (1). To make the analysis of urinary proteins maximally useful, it will be necessary to discover the origin of each spot seen, especially those not seen before or those altered in response to disease. Many of the proteins being studied are not plasma proteins and are present only in trace amounts and thus have not been identified. Techniques of isolation, antisera production, amino acid analysis, and in some cases determination of residual enzymic activities must be improved and applied systematically in order to identify the nonplasma proteins.

We thank Dr. Alan Solomon (University of Tennessee Center for Health Science, Knoxville) for supplying samples of urine from multiple myeloma patients and to Ms. Hazel Hill for excellent technical assistance. This work is supported by the U.S. Dept. of Energy under contract no. W-31-109-ENG-38.

\section{References}

1. Anderson, N. G., Anderson, N. L., and Tollaksen, S. L., Proteins of human urine. I. Concentration and analysis by two-dimensional electrophoresis. Clin. Chem. 25, 1199-1210 (1979).

2. Frey, B. M., Frey, F. J., Wegmuller, E., and Hooler, J., Proteinuria and kidney transplantation. A quantitative immunochemical study of 7 protein clearances during the first 50 days following implantation of cadaver kidney. Schweiz. Med. Wochenschr. 107, 81-90 (1977).

3. Rudman, D., Chawla, R. K., de Rio, A. E., and Hollins, B., Isolation of a novel glycoprotein from the urine of a patient with chronic myelocytic leukemia. J. Clin. Invest. 53, 868-874 (1974).

4. Roto, P., Urinary beta 2-microglobulin related to chronic low level exposure to metallic cadmium dust in Finnish cadmium processing workers. Scand. J. Work Environ. Health 4, 131-136 (1978).
5. Castleman, B., Case records of the Massachusetts General Hospital: Normal laboratory values. N. Engl. J. Med. 290, 39-49 (1974).

6. Berggård, I., Plasma proteins in normal human urine. In Proteins in Normal and Pathological Urine. Y. Manuel, J. P. Revillard, and H. Betuel, Eds., Karger, Basel/New York, NY, 1970, pp 7-19.

7. McGarry, E., Sehon, A. H., and Rose, B., The isolation and electrophoretic characterization of the proteins in the urine of normal subjects. J. Clin. Invest. 34, 832-844 (1955).

8. Miyasato, F., and Pollak, V. E., Serum proteins in urine: An examination of some of the effects of some methods used to concentrate urine. J. Lab. Clin. Med. 67, 1036-1043 (1966).

9. Vesterberg, O., and Hansen, L., A new procedure for concentration and analytical isoelectric focusing of proteins. Biochim. Biophys. Acta 534, 369-373 (1978).

10. Anderson, N. G., Anderson, N. L., Tollaksen, S. L., et al., Analytical techniques for cell fractions. XXV. Concentration and twodimensional electrophoretic analysis of human urinary proteins. Anal. Biochem. 95, 48-61 (1979).

11. Edwards, J. J., Anderson, N. G., Tollaksen, S. L., et al., Proteins of human urine. II. Identification by two-dimensional electrophoresis of a new candidate marker for prostatic cancer. Clin. Chem. 28, 160-163 (1982).

12. Anderson, N. G., and Anderson, N. L., Analytical techniques for cell fractions. XXI. Two-dimensional analysis of serum and tissue proteins: Multiple isoelectric focusing. Anal. Biochem. 85, 331-340 (1978).

13. Anderson, N. L., and Anderson, N. G., Analytical techniques for cell fractions. XXI. Two-dimensional analysis of serum and tissue proteins: Multiple gradient-slab electrophoresis. Anal. Biochem. $\mathbf{8 5}$, 341-354 (1978).

14. Edwards, J. J., Anderson, N. G., Nance, S. L., and Anderson, N. L., Red cell proteins. I. Two-dimensional mapping of human erythrocyte lysate proteins. Blood 53, 1121-1132 (1979).

15. Giometti, C. S., Anderson, N. G., Tollaksen, S. L., et al., Analytical techniques for cell fractions. XXVIII. Use of heart proteins as reference standards in two-dimensional electrophoresis. Anal. Biochem. 102, 47-58 (1980).

16. Anderson, N. L., and Hickman, B. J., Analytical techniques for cell fractions. XXIV. Isoelectric point standards for two-dimensional electrophoresis. Anal. Biochem. 93, 312-320 (1979).

17. Frearson, N., Taylor, R. D., and Perry, S. V., A protein in urine associated with muscle disease and muscle damage. Br. Med. J. 282 2002-2003 (1981).

18. Zak, R., Etlinger, J., and Fischman, D. A., Studies on the frac- 
tionation of skeletal and heart muscle. Excerpta Med. ICS 240 , $160-175$ (1972).

19. Towbin, H., Staehelin, T., and Gorden, J., Electrophoretic transfer of proteins from polyacrylamide gels to nitrocellulose sheets: Procedures and some applications. Proc. Natl. Acad. Sci. USA 76, 4350-4354 (1979).

20. Frearson, N., Taylor, R. D., and Perry, S. V., Proteins in the urine associated with Duchenne muscular dystrophy and other neuromuscular diseases. Clin. Sci. 61, 141-149 (1981).

21. Anderson, L., and Anderson, N. G., High resolution two-dimen sional electrophoresis of human plasma proteins. Proc. Natl. Acad. Sci. USA 74, 5421-5425 (1977).

22. Tollaksen, S. L., and Anderson, N. G., Two-dimensional electrophoresis of human urinary proteins in health and disease. In Electrophoresis '79, Advanced Methods and Clinical Applications. B. J. Radola, Ed., W. de Gruyter and Co., New York, NY, 1980, pp 404-414.
23. Gahmberg, C. G., and Andersson, L. C., Leukocyte surface origin of human $\alpha_{1}$-acid glycoprotein (orosomucoid). J. Exp. Med. 148 507-521 (1978)

24. Friberg, L., Health hazards in the manufacture of alkaline accumulators with special reference to chronic cadmium poisoning: A clinical and experimental study. Acta Med. Scand. 138, Suppl. 240 , $1-124$ (1950).

25. Poulik, M. D., Farrah, D., Malik, G. H., et al., Low molecular weight urinary proteins. I. Partial amino acid sequence of the retinol-binding protein of man and dog. Biochim. Biophys. Acta 412, 326-334 (1975).

26. Barragry, J. M., France, M. W., Carter, N. D., et al., Vitamin D metabolism in nephrotic syndrome. Lancet ii, 629-632 (1977).

27. Bergsagel, D. E., Treatment of plasma cell myeloma. Ann. Rev. Med. 30, 431-441 (1979).

28. Anderson, N. L., Nance, S. L., Pearson, T. W., and Anderson, N. G., Specific antiserum staining of human plasma proteins immobilized on nitrocellulose. Electrophoresis, in press (1982). 